\title{
MERGE: Modelling erosion resistance for gully erosion - a process based model of erosion from an idealised linear gully
}

\author{
M. E. Roberts ${ }^{1,2 *}$ \\ ${ }^{1}$ Australian Rivers Institute, Griffith Univerity \\ ${ }^{2}$ School of Mathematics and Statistics, University of Melbourne
}

*Griffith University, Kessels Road, Nathan, Queensland Australia

Corresponding author: Melanie Roberts, m.roberts2@griffith.edu.au 


\begin{abstract}
Gullies are responsible for as much as $40 \%$ of the accelerated erosion impacting the Great Barrier Reef lagoon. Consequently, to protect the reef from the impacts of poor water quality associated with eroded sediment the remediation of gullied landscapes is important. The geographic location and geomorphic characteristics of gullies affects their erosion characteristics and the extent to which eroded sediments may be transported to the reef. Existing models of gully erosion are predominantly empirical in nature, and are poorly suited to represent the potential benefits of different interventions in the data scarce environment that exists. Queensland Government, through the Queensland Water Modelling Network, identified the development of process-based models of gully erosion as necessary to support efforts to protect the reef. MERGE (Modelling Erosion Resistance for Gully Erosion) was developed to address this need. MERGE exhibits the expected characteristics for gully erosion including achieving a steady concentration under constant conditions, the development of a depositional layer, as well as first flush effects and hysteresis in the dynamic case. Analytical steady state solutions are found to be excellent approximations to the full dynamic solutions. The suitability of the model to represent interventions is demonstrated for the example cases of porous check dams and improved ground cover.

keywords: mathematical modelling remediation rill
\end{abstract}

\title{
Summary
}

This paper presents MERGE (Modelling Erosion Resistance for Gully Erosion), a new model to describe how much sediment will be delivered to streams because of gully erosion. The model is process-based and is able to represent actions taken to rehabilitate gullies and reduce erosion. MERGE will help improve decisions about gully remediation to protect coastal ecosystems.

\section{Introduction}

Erosion from gullies is a significant safety, economic and environmental issue. The formation and growth of gullies undermines essential infrastructure such as roads and housing, 
leads to loss of productive landscape, and is responsible for the export of tonnes of sediment, with associated particulate nutrients, to the riverine and marine environments. In Queensland, the primary concern with gully erosion is their disproportionate impact on the Great Barrier Reef (GBR). The world heritage listed GBR is under threat from climate change and poor water quality (Great Barrier Reef Marine Park Authority, 2019). Sediment and nutrients transported from catchments in the GBR significantly impact water quality and ultimately the health and recovery of the reef (Great Barrier Reef Marine Park Authority, 2019). Suspended sediment reduces light availability and impedes seagrass growth (Wooldridge, 2017), while high nutrient loads stress vulnerable coral species (Waterhouse et al., 2017). Due to complex biogeochemical interactions of sediment and nutrients, eroded sediment contributes to poor water quality through particulate and dissolved nutrients, in addition to sedimentation and high turbidity (Garzon-Garcia et al., 2018). Despite occupying only a very small percentage of the landscape, recent studies have shown gullies are responsible for as much as $40 \%$ of the total exported sediment impacting the GBR (Brooks et al., 2018). Due to their disproportionate impact on the reef, gullies present an opportunity for targeted interventions to reduce erosion at the source, and thereby limit the amount of sediment that will reach the GBR. However, these interventions can be costly, requiring massive engineering works to stabilise the gully and reduce the likelihood of continued erosion. Alternatives such as changed stocking patterns and the construction of porous check dams are typically lower cost, but are unlikely to be effective in all cases. Moreover, as gullies naturally stabilise over time, the largest gullies are not necessarily going to be the most productive in the future - preventing a currently small gully from accelerating into a massive gully complex will likely have greater benefit to the GBR than works on a mostly stabilised larger system, as well as being more cost effective. The connectivity of gullies to the riverine system, and through to the GBR, is also a factor in understanding the potential benefits of intervention. Identifying the appropriate treatment for different gullies is a complex process that will be aided by mathematical modelling to describe the erosion from gullies and the potential impact of different interventions.

This paper presents MERGE, a new model for gully erosion. MERGE is a process-based model that balances the power available from the flow with the power required to entrain sed- 
iment from the gully floor and walls within a conservation of mass framework. MERGE is designed to capture the physical interactions of erosion events in order to explore the benefit of different interventions. Process-based models were identified as critical to support gully interventions for the protection of the GBR (Prosser, 2018). Although motivated by the GBR, MERGE is suitable to apply to investigate gully erosion in any region not dominated by landslide or freeze-thaw dynamics.

Previous models of gully erosion are predominantly empirical and are poorly suited for investigating interventions. Two exceptions to this empirical approach are the conceptual SedNet models (Wilkinson et al., 2008) and the process-based sheet and rill erosion models of Hairsine and Rose (Hairsine and Rose, $1992 a, 9$ ), which have been adapted to gullies (Rose et al., 2014,0). The Dynamic SedNet models have been adapted to incorporate the benefit of interventions through an empirical management factor, however this requires an a priori knowledge of the erosion reduction achieved by each intervention. Being process-based, the models of Hairsine and Rose are better suited to representing interventions. However, as shown by Roberts (2019), scaling these models to large flow events results in inconsistencies. Nevertheless, the understanding of gully erosion processes provided by these models represented a significant advancement towards process-based models suitable for representing and informing interventions. MERGE builds upon the work of Hairsine and Rose, in particular through the incorporation of a depositional layer and the concept of re-entrainment, and the use of an erosion resistance term. MERGE is an extension of the model presented in Roberts (2019).

This paper is organised as follows. In the next section I introduce the mathematical framework for the model, then in Section 3 describe the numerical solution method to the model. Steady state solutions are explored in Section 4, while Section 5 describes the method employed to represent interventions. Results and discussion for all three approaches, dynamic, steady state and with interventions, are given in Section 6 before concluding with some remarks in Section 7. A reference summary of symbols is provided in Appendix A. 


\section{The model}

Consider an ideal homogeneous gully of rectangular geometry and constant shallow slope. The gully is situated such that rain events will generate sufficient runoff to overcome the resistance of the soil to erosion. Rainfall over the drainage area of the gully will result in a known flux of runoff $Q\left[\mathrm{~m}^{3} / \mathrm{s}\right]$ that enters the gully via the head. This runoff cascades over the head of the gully in a waterfall that extends a distance $L_{h}[\mathrm{~m}]$ into the gully. This flux of water, without loss due to infiltration or other means, then flows through the channel of the gully of length $L[\mathrm{~m}]$, width $W[\mathrm{~m}]$ and slope $S$ [1]. As the runoff flows through the gully it entrains sediment and transports it down the channel. Some fraction of this sediment will settle out of the water column, forming a depositional layer atop the original soil. This depositional layer is available for re-entrainment, but while present acts as a shield, reducing the erosion of the original soil matrix (Hairsine and Rose, 1992a). The term 're-entrainment' was introduced by Hairsine and Rose to differentiate between the entrainment of the original soil matrix and of the depositional layer; this paper uses this terminology, with 'entrainment' referring to the original soil matrix and 're-entrainment' to the depositional layer. Fig. 1 shows the geometry of the idealised linear gully considered in this paper. MERGE considers runoff events that are sufficiently large to overcome the erosion resistance of the soil, and result in a flow depth that is sufficiently large to shield the gully floor from rainfall-driven detachment. Rainfalldetachment dominates erosion during the initial stages of an event. However, once the flow reaches approximately three times the diameter of the raindrops, rainfall-detachment ceases (Hairsine et al., 1992).

Infiltration of the runoff into the gully walls, and undermining of the side walls and head due to erosion at the base, can lead to mass slumping and gravity-driven collapse. Such events can deliver large amounts of sediment to the water column and alter the runoff dynamics, accelerating erosion processes. Gravity-driven erosion constitutes an additional sediment-source, however is not currently captured in this model.

[Figure 1 about here.] 
The objective is to determine the mass of sediment delivered to the the river network as a result of gully erosion. A conservation of mass approach for the concentration of sediment in the water column is therefore adopted. The change in sediment in the water column is described by the conservation of mass equation with a source due to entrainment and sink due to deposition. That is

$$
W \frac{\partial(C d)}{\partial t}+\frac{\partial(C Q)}{\partial x}=\eta-\delta
$$

where $C\left[\mathrm{~kg} / \mathrm{m}^{3}\right]$ is the sediment concentration, $\eta[\mathrm{kg} / \mathrm{ms}]$ is the rate of entrainment, $\delta[\mathrm{kg} / \mathrm{ms}]$ is the rate of deposition, $d[\mathrm{~m}]$ the depth of flow within the gully, and $Q$ and $W$ are the previously defined runoff flux and gully width. The conservation of mass equation (1) is solved subject to a boundary condition of known sediment concentration entering the gully $C(0, t)=$ $C_{0}(t)$. The initial concentration of sediment within the water column is the concentration of sediment entering the gully at time $t=0$, that is $C(x, 0)=C_{0}(0)$. In the next sections the rates of entrainment and deposition are described. Furthermore, it is convenient to consider each component of the gully individually. Therefore, the gully is divided into its component parts of head and channel to consider the rates of entrainment and re-entrainment.

\subsection{Deposition}

Sediment settles out of the water column at the rate $b C w_{s}$, where $w_{s}[\mathrm{~m} / \mathrm{s}]$ is the setting velocity of the sediment, and $b$ is the ratio of the sediment concentration at the base of the water column relative to the average concentration, which represents a concentration gradient within the water column. Although a constant settling velocity is assumed, in practice settling velocities are higher in suspensions that exceed $1 \%$ by weight due to the increased number of inter-particle collisions. Where high concentrations are expected, using a higher settling velocity may be warranted. Sediment is assumed to settle equally across the width of the gully, and thus the rate of deposition per gully length is $\delta=W b C w_{s}[\mathrm{~kg} / \mathrm{ms}]$. This deposited sediment forms a layer, the depositional layer, overlaying the original soil matrix, and is available to be re-entrained. This layer has no effective resistance to erosion, and therefore will be entrained at a greater rate than the underlying original soil would be. 


\subsection{Entrainment}

MERGE reflects the physical processes of erosion using a power argument; power available to erode is balanced against the power required to lift sediment into the water column. The erosive power of the runoff is due to the loss of potential energy as the water looses height. As the water cascades over the gully head the rate of change of potential energy, per unit length of gully, is the waterfall power $\Psi=\rho g Q(D-d) / L_{h}[\mathrm{~W} / \mathrm{m}]$, where $\rho\left[\mathrm{kg} / \mathrm{m}^{3}\right]$ is the water density, $g\left[\mathrm{~m}^{2} / \mathrm{s}\right]$ is gravitational acceleration, $D=D_{0}+S x[\mathrm{~m}]$ is the gully depth a distance $x[\mathrm{~m}]$ from the start of the gully with bottom slope $S, d[\mathrm{~m}]$ is the depth of flow within the channel, and therefore $D-d$ is the height through which the waterfall drops above the flow within the channel. The waterfall power is assumed to act equally over the gully floor at the head. As the water travels down channel it looses height due to the slope of the gully floor. The power generated by this loss in potential energy is the stream power $\Omega=\rho g Q S$ $[\mathrm{W} / \mathrm{m}]$, which is assumed to act equally over the wetted perimeter of the gully channel. The wetted perimeter is the perimeter of the cross-sectional area that is 'wet' or under water during a flow event. The power available to do work on the gully floor and walls is some fraction $k$ of the total waterfall and stream power generated (as energy is also dissipated via frictional heating, noise etc.).

The rate of entrainment of sediment $\eta$ due to the waterfall and stream power is given by equating the power required to entrain sediment with the power available for entrainment. The power available to entrain sediment must be sufficient to overcome the cohesion of the soil and static friction, before lifting the sediment into the water column. I adapt the approach of Hairsine and Rose $(1992 a, 9)$ and introduce $J$ [Ws/kg], the erosion resistance of the soil. The erosion resistance of the soil is the energy required to break the cohesion of a unit mass of soil. Highly dispersive sodic soils will have a low resistance (easy to erode), while bedrock will have a very high resistance (hard to erode). The erosion resistance is also affected by ground cover and other vegetation, or can be artificially enhanced for example using rock chutes or capping. In an analogous way I define $F[\mathrm{Ws} / \mathrm{kg}]$ to be the energy required to overcome static friction per unit mass of sediment, however $F$ is small in comparison with the other terms in the equations and for practical purposes can be neglected. Once the cohesion of the soil 
and static friction have been overcome, sediment will be entrained into the water column to a height $h \leq d[\mathrm{~m}]$, the depth of the water. The power required to entrain the sediment at a rate $\eta$ is a function of the immersive weight of the sediment, $(\sigma-\rho) g / \sigma$, and the height of entrainment, $h$, for a sediment of density $\sigma\left[\mathrm{kg} / \mathrm{m}^{3}\right]$. For simplicity, I introduce $\beta=(\sigma-$ $\rho) g h / \sigma[\mathrm{Ws} / \mathrm{kg}]$, and thus the power required to overcome the erosion resistance of the soil and static friction and then entrain sediment at the rate $\eta$ is $J+F+\beta$.

Equating the power available to the power required to entrain gives $\eta=(k \Omega+H(x-$ $\left.\left.L_{h}\right) k \Psi\right) /(J+F+\beta)$, where $H\left(x-L_{h}\right)$ is the Heaviside function such that $H=1$ at the gully head, $x \leq L_{h}$, and $H=0$ within the gully channel, $x>L_{h}$. As in Roberts (2019) I assume that there exists a natural carrying capacity of the flow $C^{*}\left[\mathrm{~kg} / \mathrm{m}^{3}\right]$, and therefore that the rate of entrainment decreases linearly as the sediment concentration approaches this carrying capacity. The carrying capacity is independent of the flow conditions, and instead represents a physical upper limit to the transport of sediment in free-flowing water. Sediment concentrations in excess of the carrying capacity operate under different physical regimes, for example debris flows or mudslides, which are not considered here. Entrainment is therefore constrained by the term $1-C / C^{*}$. The carrying capacity term represents the energy required to maintain sediment in suspension within the stream flow and acts to reduce the proportion of stream (or waterfall) power available to do work on the gully floor and walls. The effective rate of entrainment is therefore

$$
\eta=\frac{k \Omega+H\left(x-L_{h}\right) k \Psi}{J+F+\beta} \frac{C^{*}-C}{C^{*}}
$$

It is convenient to consider the rates of entrainment in each component of the gully individually. I therefore divide the gully into its component parts and consider the rates of entrainment and re-entrainment for each component. Total entrainment within each region (per unit length) is the sum of the component parts. Thus in the gully head $\eta=\eta_{e h}$, while in the gully channel $\eta=\eta_{e w}+\eta_{e f}+\eta_{r}$, where the various forms of entrainment are defined in the next two subsections. 


\subsubsection{Entrainment in the gully head $0 \leq x \leq L_{h}$}

Within the gully head power is available from both the waterfall and stream power. Following Rose et al. (2014), I assume that within the gully head region sediment is immediately re-entrained as it is deposited, and thus no depositional layer forms. I further assume that all erosion is from the gully floor, noting that this will represent an under-estimate of the total sediment contribution. As the waterfall cascades over the side of the gully it will entrain from the gully walls, which is an additional source of entrainment not represented by this model. This entrainment is however expected to be small in comparison with the entrainment from the gully floor in this region. A potentially larger source of entrainment is gravity collapse, which is linked to the massive growth of the gully and the delivery of large amounts of sediment to the water column. Modelling of gravity collapse however requires a different approach than is considered by this model. The levee-failure methods of Fukuoka and Tabata (2019) could potentially be used to determine the rate of sediment source due to gravity-driven collapse. This rate of sediment supply would be incorporated into the conservation of mass equation as an additional source term.

The power required to re-entrain the deposited sediment $\delta$ is $(F+\beta) \delta$, and thus the residual effective power available to entrain the original soil matrix is $k \Omega\left(C^{*}-C\right) / C^{*}-(F+$ $\beta) \delta$. Thus the total entrainment from the gully in the head region, including immediate reentrainment of all deposited material, is

$$
\eta_{e h}+\delta=\left[\frac{k(\Omega+\Psi)}{J+F+\beta}-\delta \frac{F+\beta}{J+F+\beta}\right]\left(\frac{C^{*}-C}{C^{*}}\right)+\delta,
$$

where the subscript $e$ refers to the entrainment (e) of a cohesive sediment (that is, with $J \neq$ 0 ) within the gully head $(h)$ region. As I consider only entrainment from the floor of the gully head, the conservation of mass equation is

$$
W \frac{\partial(C d)}{\partial t}+\frac{\partial(C Q)}{\partial x}=\eta_{e h}+\delta-\delta=\left[\frac{k(\Omega+\Psi)}{J+F+\beta}-\delta \frac{F+\beta}{J+F+\beta}\right]\left(\frac{C^{*}-C}{C^{*}}\right)
$$

where $\delta\left(\frac{F+\beta}{J+F+\beta}\right)$ represents the effective decrease in entrainment from the original soil matrix due to the immediate re-entrainment of all deposited material. 


\subsubsection{Entrainment in the gully channel $L_{h}<x \leq L$}

Within the gully channel waterfall erosion is negligible and entrainment is driven by stream power. Within the gully channel the rates of entrainment are typically much less than within the gully head region, and thus a depositional layer is expected to form atop the gully floor. While this depositional layer is non-cohesive $(J=0)$, the original soil matrix of the floor and walls is cohesive $(J>0)$. Two scenarios must therefore be considered (i) a permanent depositional layer, and (ii) a transient depositional layer, as exists in the gully head region. In the first scenario, the rate of entrainment is insufficient to fully erode the depositional layer, which will either maintain (steady state scenario) or increase its mass. If the rate of entrainment is sufficient to fully entrain the depositional layer, any remaining stream power will lead to the entrainment of the underlying soil matrix. As sediment is not deposited on the gully walls, the rate of entrainment from the walls is the same in either scenario.

\section{Gully walls}

It is assumed that the stream power acts equally across the wetted perimeter. Thus the effective stream power acting on the gully walls inundated to a depth $d$ per unit length is the proportion of the wetted perimeter occupied by the walls, that is $2 d /(W+2 d)$. Entrainment from the gully walls is therefore

$$
\eta_{e w}=\frac{2 d}{W+2 d} \frac{k \Omega}{J+F+\beta} \frac{C^{*}-C}{C^{*}} .
$$

Equation (5) assumes that the depth of deposited sediment is negligibly small in comparison with the depth of flow.

\section{Gully floor}

The depositional layer is assumed to uniformly cover the width of the gully floor, which occupies $W /(W+2 d)$ of the wetted perimeter. As the depositional layer shields the underlying soil, the rate of entrainment from the original soil matrix must consider the re-entrainment of the depositional layer. If $M[\mathrm{~kg} / \mathrm{m}]$ is the mass of the depositional layer per unit length, and $\mathcal{M}[\mathrm{kg} / \mathrm{ms}]$ is the corresponding rate required to instantaneously remove the layer $M$, 
then the rates of re-entrainment $(r)$ and entrainment from the gully floor $(e f)$ are

$$
\begin{aligned}
\eta_{r}=\min \left(\frac{W}{W+2 d} \frac{k \Omega}{F+\beta} \frac{C^{*}-C}{C^{*}}, \mathcal{M}\right) \\
\eta_{e f}= \begin{cases}0 & \eta_{r} \leq \mathcal{M} \\
\frac{W}{W+2 d} \frac{k \Omega}{J+F+\beta} \frac{C^{*}-C}{C^{*}}-\eta_{r} \frac{F+\beta}{J+F+\beta} & \eta_{r}>\mathcal{M} .\end{cases}
\end{aligned}
$$

The mass of the depositional layer is given by

$$
\frac{\partial M}{\partial t}=\delta-\eta_{r}
$$

which is solved subject to the initial condition $M(x, 0)=M_{0}$, the initial mass of the depositional layer. The initial mass of the depositional layer will depend on how recently previous erosion events occurred, soil type, and any rainfall-detachment at the start of the current flow event.

\section{Dynamic Solution Approach}

To explore the response of the gully to both constant and variable runoff events I solve the dynamic conservation of mass equation (1) with (3) to (8), subject to the initial condition $C(x, 0)=C_{0}$ and boundary condition $C(0, t)=C_{0}$ using numerical techniques.

The numerical method of lines approach (Schiesser, 1991), discretised in space, is implemented in Python v3.6.5 using the numpy odeint ordinary differential equation routine. Method of lines is a general procedure for the solution of time-dependent partial differential equations. A central difference scheme is used to resolve the spatial derivatives at internal nodes within the gully head and channel regions, with backward and forward difference used for the boundary nodes. The internal boundary between the head and channel, across which there is a discontinuity in the erosive power of the flow, is resolved using a backward difference scheme. To simplify the numerical solution, the following approximations were incorporated: the flux $Q$ is constant within the gully, that is $Q(x, t)=Q(t)$, and the height $D-$ $d$ through which the waterfall drops is approximated by $D_{0}-d$, a constant in $x$. The constant flux assumption is valid where the time rate of change of the flux is small in compar- 
ison with the velocity of the flow, while the waterfall depth approximation will lead to an underestimate in the waterfall power available for erosion. These assumptions mean that the flow depth as well as the waterfall and stream power are functions of time only. The gully is discretised with a node every half a metre through the head and channel. The numpy odeint routine employs an adaptive timestep. The maximum timestep permitted was never more than 0.36 seconds. Gibbs phenomena (oscillations in the solution) are evident at the discontinuities in the erosive power or the flow, which is not unexpected. These discontinuities occur at the transition from the head to the channel (due to the waterfall power going to zero), and in Section 6.3 at the porous check dams.

\section{Steady state solutions}

Previous research suggests the existence of a steady state solution (Hairsine, 1988; Hairsine and Rose, 1992a), which is investigated here. At steady state the mass of the depositional layer is constant, therefore the rate of entrainment and deposition within the gully channel are equal, that is $\eta_{r}=\delta$, which implies

$$
C=C^{*}\left(1-\frac{\delta^{*}}{\delta^{*}+\zeta_{r}}\right)<C^{*}
$$

a constant concentration where $\delta^{*}$ is the maximum deposition rate given by $C=C^{*}$, and $\zeta_{r}=\frac{W}{W+2 d} \frac{k \Omega}{F+\beta}$. In order for (9) to satisfy the conservation of mass equation (1) with $\eta_{\mathrm{r}}=$ $\delta$ requires $\eta_{e w}=0$, a condition that cannot be satisfied. Thus the steady depositional layer presumed in Hairsine and Rose (1992b) and related papers is not a valid solution within gullies. This result is not unexpected. With $\eta_{r}=\delta$, the spatial derivative of the mass flux $C Q$ is positive due to entrainment from the gully walls. Neglecting the carrying capacity term for a moment, this gives a linearly increasing concentration with distance. However, in order for re-entrainment and deposition to be in balance, this would require that the re-entrainment also increased linearly with distance since deposition is a linear function of the concentration. Under constant flux conditions, re-entrainment is constant in $x$ outside of the carrying capacity term, and therefore is unable to adapt to balance the increased deposition, breaching the steady state requirement. Including the carrying capacity term leads to a similar contra- 
diction. Solution of the steady state conservation of mass equation with entrainment from the walls under a carrying capacity constraint results in a solution of the form $C=C^{*}(1-$ $\left.e^{-x}\right)$, which is likewise an increasing concentration, leading to the same contradiction between deposition and re-entrainment as before. I therefore conclude that a non-zero steady state depositional layer cannot arise.

Interest, however, is not in the dynamics of the depositional layer, but rather in the mass flux of sediment delivered to the stream network. I therefore explore conditions under which a steady state concentration may arise within the gully channel. To simplify the application of the boundary conditions at the entrance to the channel region, I introduce the translations $\widehat{x}=x-L_{h}$ and $\widehat{C}=C-C(\widehat{x}=0)=C-C_{L h}$ and use the $\widehat{ }$ notation to refer to variables on this translated coordinate system. That is, consider solutions to

$$
\begin{gathered}
Q \frac{\partial \widehat{C}}{\partial \hat{x}}=\widehat{\eta}_{\mathrm{ew}}+\widehat{\eta}_{\mathrm{r}}+\widehat{\eta}_{\mathrm{ef}}-\widehat{\delta} \\
\widehat{C}(0)=0,
\end{gathered}
$$

with $\widehat{\delta}=W b w_{s}\left(\widehat{C}+C_{L h}\right)$ and the carrying capacity in the entrainment terms now $1-(\widehat{C}+$ $\left.C_{L h}\right) / C^{*}$.

If $\widehat{\delta}>\widehat{\eta}_{\mathrm{r}}$, then the depositional layer is permanently present and $\widehat{\eta}_{\mathrm{ef}}=0$. This gives rise to the quasi-steady state concentration

$$
\widehat{C}_{\mathrm{SS}_{r}}=\left(\frac{C^{*}\left(\widehat{\zeta}_{\mathrm{ew}}+\widehat{\zeta}_{\mathrm{r}}\right)}{\widehat{\delta}^{*}+\widehat{\zeta}_{\mathrm{ew}}+\widehat{\zeta}_{\mathrm{r}}}-C_{L h}\right)\left[1-\exp \left(-\frac{\hat{x}}{C^{*} Q}\left(\widehat{\delta}^{*}+\widehat{\zeta}_{\mathrm{ew}}+\widehat{\zeta}_{\mathrm{r}}\right)\right)\right]
$$

where $\widehat{\zeta}_{\mathrm{ew}}=\frac{2 d}{W+2 d} \frac{k \Omega}{J+F+\beta}$ and $\widehat{\zeta}_{\mathrm{r}}=\frac{W}{W+2 d} \frac{k \Omega}{F+\beta}$. This represents an exponentially increasing concentration that is constrained by the carrying capacity $C^{*}$. The implicit requirement underpinning this solution is that the effective stream power is sufficient to maintain erosion but not so large as to completely erode the depositional layer. Far from the gully head this condition is satisfied, since $\left.\frac{\partial \widehat{M}}{\partial t}\right|_{x \rightarrow \infty}=\widehat{\delta}^{*} \widehat{\zeta}_{\text {ew }} /\left(\widehat{\delta}^{*}+\widehat{\zeta}_{\text {ew }}+\widehat{\zeta}_{\mathrm{r}}\right)>0$. However, $\left.\frac{\partial \widehat{M}}{\partial t}\right|_{x=0}=$ $-\widehat{\zeta}_{\mathrm{r}}+C_{L h}\left(\widehat{\zeta}_{\mathrm{r}}+\widehat{\delta}^{*}\right) / C^{*}$, which may be negative, depending on the concentration entering the channel. If the concentration of sediment exiting the gully head is close to the carrying 
capacity of the flow then this will be positive, and the mass of the depositional layer will increase over time.

In the case where the depositional layer is continuously re-entrained, allowing for entrainment from the original soil matrix, the net entrainment is given by

$$
\frac{k \Omega}{J+F+\beta}\left(1-\frac{\widehat{C}-C_{L h}}{C^{*}}\right)-\frac{F+\beta}{J+F+\beta} \widehat{\delta},
$$

which gives rise to the steady state concentration

$$
\widehat{C}_{\mathrm{SS}_{\mathrm{e}}}=\frac{A C^{*}-C_{L h}\left(A+B C^{*}\right)}{A+B C^{*}}\left[1-\exp \left(\frac{-\hat{x}}{Q C^{*}}\left(A+B C^{*}\right)\right)\right],
$$

where $A=\frac{k \Omega}{J+F+\beta}$ and $B=\frac{F+\beta}{J+F+\beta} W b w_{s}$. This condition requires the effective power available for erosion across the floor exceeds that required to re-entrain the depositional layer, that is $\frac{k \Omega}{J+F+\beta}>W b w_{s} \widehat{C}_{\mathrm{SS}_{\mathrm{e}}}$.

Within the head region of the gully a depositional layer does not form, as deposited sediment is assumed to be continuously re-entrained. Neglecting the influence of gully slope on the waterfall power, $\Psi$, is a constant and the steady state conditions are therefore analogous to (14). On the original domain this is

$$
C_{\mathrm{SS}_{h}}=\frac{A_{2}}{B}+\left(C^{*}-\frac{A_{2}}{B}\right)\left\{\frac{A_{2}-B C_{0}}{A_{2}-B C_{0}-B\left(C^{*}-C_{0}\right) \exp \left[\frac{-x}{C^{*} Q}\left(A_{2}-B C^{*}\right)\right]}\right\}
$$

where $A_{2}=\frac{k(\Omega+\Psi)}{J+F+\beta}$, and $B$ is as previously defined. In the limit $C_{0}=C^{*}$, the steady state concentration within the head region is $C_{\mathrm{SS}_{h}}=C^{*}$ due to the assumption that a depositional layer cannot form. That is, all sediment deposited out must be immediately re-entrained. As the concentration is already at the carrying capacity, entrainment from the original soil matrix is prevented and the concentration stays constant. For the non-depositional layer assumption to be valid, the waterfall power must be sufficient to immediately re-entrain all deposited sediment. 


\section{Applying MERGE to represent interventions}

The ability to represent gully interventions was a key motivator for the development of MERGE. Gully interventions are varied, however all target one or more of three actions: reducing runoff (either volume or velocity), increasing the erosion resistance of the soil, and increasing deposition. As deposition is unable to be directly targeted, increasing deposition equates to reducing the runoff velocity thereby increasing residence time, which enables a higher mass of sediment to deposit over the same distance of flow. As examples, increasing ground cover, particularly of native grasses, will increase infiltration (reducing runoff volume) and increase surface roughness (decreasing runoff velocity) within the drainage area as well as increasing the erosion resistance of the soil within the gully. Gully reshaping aims to eliminate the waterfall and reduce runoff slope, decreasing runoff velocity. Porous check dams reduce runoff velocity and increase residence times, while stock exclusion promotes revegetation. Chemical soil treatments, such as the application of gypsum, support initial vegetation establishment, increasing roughness and hence decreasing runoff flux.

To illustrate the ability of MERGE to represent interventions I explore two possible actions, (i) increasing ground cover within the gully, and (ii) the installation of porous check dams. Increasing ground cover within the gully will both increase the erosion resistance of the soil (increase $J$ ) and decrease the flow velocity, and hence the flux $Q$. I illustrate the potential benefits of increasing ground cover through the Manning's roughness coefficient $n$. These results are an under-estimate, as the erosion resistance, $J$, is held constant, when in practice it will increase as the ground cover will act as a shield, protecting the soil from the action of the flow. The method of Arcement Jr and Schneider (1989) for selecting Manning's roughness coefficients in channels is adapted to determine the new Mnaning's roughness coefficient post intervention. Arcement Jr and Schneider (1989, Eq. 3) apply additive corrections to the base number due to surface irregularities, channel cross-section shape and size, obstructions, and vegetation and flow conditions. Modelling the porous check dams as an obstruction to the flow, the corrected Manning's number is therefore

$$
n=n_{\text {base }}+n_{\mathrm{gc}}+n_{\mathrm{pcd}}
$$


where $n_{\text {base }}$ is the base coefficient value, $n_{\mathrm{gc}}$ is the correction due to vegetation (including ground cover), and $n_{\text {pcd }}$ is the correction due to the porous check dams. Adjustments due to channel cross section, and surface irregularities do not apply in this case. As the channel is rectangular, a correction due to meandering is also not required.

The value for $n_{\mathrm{gc}}$ was determined by fitting an exponential curve to the values in Arcement Jr and Schneider (1989, Table 2) assuming a ground cover height of $20 \mathrm{~cm}$ and that 'small' corrections correspond to a flow depth twice the ground cover height, 'medium' to $1.5 \times$, 'large' to $1 \times$, and 'very large' to a flow depth half the height of the ground cover. The Manning's $n$ corrections corresponding to 'small', 'medium', 'large', and 'very large' are provided in Arcement Jr and Schneider (1989, Table 2). With the ground cover assumed to cover a proportion $G$ of the gully width,

$$
n_{\mathrm{gc}}=0.1768 G \exp (-0.016 d)
$$

Porous check dams are commonly constructed by loosely inter-weaving natural timber across the width of the gully, potentially secured with a wire mesh and star pickets (Wilkinson et al., 2019). The objective is for the dams to slow the flow of water, encouraging deposition and therefore providing a surface for revegetation. I consider the influence of porous check dams on erosion for a single event. As with ground cover, the porous check dams are simulated through the Manning's roughness coefficient via the $n_{\text {pcd }}$ term in (16). The influence of porous check dams is more complex than a local change to the roughness coefficient, as the influence of the dam on the flow extends beyond the immediate location of the dam. However, rather than incorporate complex representations of the dam's influence on the flow, I model the check dam as an obstruction whose influence decays exponentially with distance. I choose the upper limit of the severe obstruction category from Arcement Jr and Schneider (1989, Table 2) adjusted for the height of the water relative to the dam, and with the previously mentioned exponential decay downstream. Thus

$$
n_{\mathrm{pcd}}=0.05 \frac{p c d_{\text {height }}}{d} \exp (-0.5 x)
$$


where $p c d_{\text {height }}[\mathrm{m}]$ is the height of the porous check dam. Directly coupling in the flow behaviour to the model will improve the representation of dams.

[Table 1 about here.]

\section{Results and discussion}

\subsection{Dynamic equations}

The erosion of an idealised gully is explored by considering two flux regimes. A constant flux of depth $d=0.2 \mathrm{~m}$, which equates to $Q=0.303 \mathrm{~m}^{3} / \mathrm{s}$ for this case study, and a dynamic flux that is sinusoidal in shape. The sinusoidal flux is described by $d=\sin (\pi t / 3600)+$ $0.001 \mathrm{~m}$ and is considered over a one hour period, which equates to a maximum flux of $3.154 \mathrm{~m}^{3} / \mathrm{s}$. Two gully erosion resistances are also considered, a highly erodible gully with $J=400 / 3600^{2} \mathrm{~W} \mathrm{~s} / \mathrm{kg}$, and a gully that is resistant to erosion with $J=400 \mathrm{~W} \mathrm{~s} / \mathrm{kg}$. The value of $J$ chosen for a highly erodible gully is sufficiently small as to be negligible, while the value chosen for the resistant gully is sufficient to prevent erosion within the channel. Other parameter values were chosen to reflect, as close as practicable, values from the Bremer gully case study in Rose et al. (2014). Consequently, the sediment density and settling velocity are somewhat higher than would typically be of primary interest in the GBR catchments at $\sigma=2320 \mathrm{~kg} / \mathrm{m}^{3}$ and $w_{s}=$ $0.05 \mathrm{~m} / \mathrm{s}$. A summary of the parameter values is given in Table 1. Unless stated otherwise, these parameter values are used for all figures.

The numerical solution of the full dynamic equations for a highly erodible gully with a constant flux indicates a rapid approach to the steady state solution, and confirms the growth of the depositional layer predicted by the steady state analysis, see Section 4 . The ratio of the erosive power available from the flow to the resistance of the sediment separates erosion dynamics in the gully into two regimes.

[Figure 2 about here.]

[Figure 3 about here.] 
For a highly erodible gully, with a clean inflow, erosion will be greatest within the head region due to the erosive power of the waterfall. On entering the channel, with the sharp decrease in erosive power, deposition will dominate until a new equilibrium is reached. This transition between the head and channel region results in a localised jump in the depositional layer. In practice, the edge of the depositional layer would not be this severe, as the transition from the waterfall region to the channel would be more gradual than the enforced discontinuity. Nevertheless, this result is consistent with the expected accumulation of sediment at transitions in the stream power. Where the power of the flow to entrain and transport sediment decreases, a local increase in deposition is expected until a new equilibrium is obtained. Similarly, where the erosive power increases, for example due to an increase in slope, additional scouring is expected.

While the constant flux case illustrates typical erosion behaviour under different regimes, a more natural runoff event will commence with a low runoff, increasing to some maximum before declining to zero. Such a dynamic event is modelled using the sinusoidal flux profile described above. Within the gully at any point in time, the erosion dynamics are not dissimilar to that of the constant flux case. For the highly erodible gully, the erosive power in the head exceeds that in the channel. Therefore, the sediment concentration grows within the head, declining rapidly at the transition to the channel, see Fig. 2. This transition zone likewise corresponds to a localised jump in the height of the depositional layer. The temporal dynamics, however, differ significantly, not least in that steady conditions will not eventuate. As the water depth increases the waterfall power decreases as $D_{0}-d$ is reduced. This introduces a wave in the sediment concentration in the head, which is transferred down channel, and is also evident in the temporal dynamics of the depositional layer, see Fig. 3. For this event the depositional layer continues to grow throughout the channel, however runoff events can occur where the depositional layer is at times depleted or decreasing.

As this model is yet to be parameterised the modelled sediment fluxes and depositional layer depths should not be considered predictive of any specific event. However, layer depths of around $5-10 \mathrm{~cm}$ are not unrealistic. Integrating the exit flux for the sinusoidal event to determine the area under the curve gives the total flux during the one hour long event to be 
approximately 61 tonnes. For reference, the case study gully in Rose et al. (2014), on which the baseline parameter values were modelled, exported $1.772 \pm 0.011 \times 10^{6}$ tonnes of sediment between their December 2009 and February 2011 surveys.

Erosion dynamics within a gully that is highly resistant to erosion exhibit some significant differences to the highly erodible case. An erosion resistance of $J=400 \mathrm{Ws} / \mathrm{kg}$ is used to model a gully that is resistant but not immune to erosion for the case study events. Fig. 4 shows the sediment flux at selected locations within the gully during an hour long runoff event for the constant and sinusoidal runoff fluxes.

[Figure 4 about here.]

In the case of the constant flux, the gully is sufficiently resistant to erosion that entrainment is constrained throughout the length of the gully. Any sediment deposited is immediately reentrained, preventing the build up of a depositional layer. In contrast to the highly erodible case, here the concentration of sediment, and hence the sediment flux, increases monotonically along the length of the gully, indicating that this system is supply limited, as opposed to transport limited. While a steady state is achieved, it takes approximately 10 times longer than for the transport limited case. This is due to the fact that sufficient sediment must be eroded such that deposition and re-entrainment, with a small amount of entrainment from the walls, will be balanced. The steady sediment flux at the gully exit is approximately one tenth that of the highly erodible case.

The longer transient phase is also evident in the sinusoidal flux case. Initially, the flow is insufficient to generate entrainment, leading to a distinct asymmetry in the flux profile. As with the constant flux case, the dynamic profile also indicates a monotonically increasing sediment flux along the length of the gully. The entrainment wave in the gully head is also significantly less pronounced than in the highly erodible case. For most of the runoff event, any deposited sediment is immediately re-entrained. An artificial depositional layer does however arise at the conclusion of the runoff event. This depositional layer is an artefact of the spatially independent flux assumption. As the runoff event concludes, the depth of water approaches zero, and thus the concentration within the water column increases, leading to an artificially 
high deposition rate. This deposition layer is however small, less than $2 \mathrm{~mm}$ high, and can therefore be neglected.

In addition to the depositional layer, other observed phenomena common to erosion in channels evident in these solutions include hysteresis and first flush. Hysteresis refers to the observations whereby the concentration in the flow is not a deterministic function of the flux. That is, the concentration at a specific flow is different between the rising and falling hydrograph. These observations suggest a temporal dynamic to erosion. I check for hysteresis by comparing the sediment concentration at the same flux on the rising and falling hydrograph for the sinusoidal flow depth. Fig. 5 shows the asymmetry in the concentration at the start of the channel region and the gully exit, calculated using $\left.C\right|_{\mathrm{Q} \text { rise }}-\left.C\right|_{\mathrm{Q} \text { fall }}$. Although small in comparison to the total sediment concentration, these results nevertheless provide support for the validity of the model.

[Figure 5 about here.]

First flush refers to the observations of a short, initial high sediment flux that rapidly falls away. The results suggest this is likely due to either a pre-existing depositional layer, see Fig. 6, or due to a high sediment concentration in the inflowing runoff, see Fig. 7. For a highly erodible gully, where the depositional layer will otherwise grow unbounded, an initial depositional layer has a negligible effect on the total sediment flux over a runoff event. However, for a gully that is resistant to erosion, this initial depositional layer produces an initially high sediment flux as the layer is rapidly entrained. As the underlying sediment is resistant to erosion, once this layer is depleted the sediment flux will sharply decline to steady state conditions. Where the gully is highly resistant to erosion the steady state is no entrainment, and thus the sediment flux decreases to zero once the depositional layer is fully entrained.

[Figure 6 about here.]

First flush effects were also observed for a high inflow concentration, however this may be an artefact of the model assumptions. As the spatial dynamics of the flux are not considered, that is $Q(x, t)=Q(t)$, the initial concentration throughout the gully is assumed to be 
that of the inflowing runoff. The high initial concentration leads to high initial sediment flux out of the gully that very rapidly approaches the steady value, as shown in Fig. 7 .

[Figure 7 about here.]

\subsection{Steady state}

Although not a true steady state, the quasi-steady state solutions are not qualitatively dis-similar from earlier descriptions of steady state behaviour observed experimentally. A steady concentration is evident, which is consistent with observations based on the sediment concentration in water samples (see the experimental results for a rainfall-detachment process of Hairsine (1988)). The existence of a depositional layer at steady concentrations is also consistent with the work of Hairsine (1988). Although this analysis indicates that a steady depositional layer is not possible, at low flows the aggregation of the depositional layer may be sufficiently slow that it may not have been observed with the techniques used to measure the depositional layer. Specific laboratory or field trials are necessary to confirm the growth of the depositional layer.

The usefulness of the steady state solution to inform interventions is explored via a comparison with the solution of the full time-dependent conservation of mass equation, (1). This comparison demonstrates that after a short time the steady state solution is an excellent approximation to the full dynamics. Under the constant flux assumption the dynamic solution approaches the steady state within 2 minutes, and by 6 minutes is indistinguishable from the steady state solution, as shown in Fig. 8.

[Figure 8 about here.]

The steady state solution was further tested by comparing the dynamic solution subject to the sinusoidal runoff flux with the solution obtained assuming that steady conditions hold at each point in time. As shown in Fig. 9, the sediment concentration is well approximated by the steady state. 
[Figure 9 about here.]

These results indicate that the analytic steady state solution can be used as a proxy for the full problem, even when the flux is non-constant. Care however must be taken to ensure that the correct steady state regime is considered, that is with or without a depositional layer present.

Figs. 10 and 11 explore the response of the sediment flux to different gully and flow parameters for selected erosion resistances between $J=0 \mathrm{Ws} / \mathrm{kg}$ and $J=50 \mathrm{Ws} / \mathrm{kg}$ under the assumption of a permanent depositional layer. Results are obtained using the analytical quasi-steady state solutions.

[Figure 10 about here.]

As clean water enters the gully (Fig. 10(a), (c), and (e)) it entrains sediment at a greater rate than it deposits out (by definition). In the head region of the gully the sediment concentration increases rapidly. As the flow enters the channel region, the erosive power of the flow instantaneously drops. Where the flow concentration is greater than the transport capacity of the channel, deposition will dominate and the concentration will approach the steady concentration $\left[C^{*}\left(\widehat{\zeta}_{\text {ew }}+\widehat{\zeta}_{\mathrm{r}}\right)\right] /\left(\widehat{\delta}^{*}+\widehat{\zeta}_{\mathrm{ew}}+\widehat{\zeta}_{\mathrm{r}}\right)($ Fig. $10(\mathrm{a})$ and $(\mathrm{b}))$, while if the flow is unable to reach its transport capacity by the end of the head region, entrainment will continue to dominate within the channel (Fig. 10 (c) - (f)). Where the inflowing concentration is higher (Fig. 10 (b), (d) and (f)), but still less than the transport capacity of the flow within the head, the concentration profiles are similar to that for the clean inflow, with the natural maximum concentration being reached quicker due to the higher starting concentration. If the concentration of the inflowing runoff is at the transport capacity for the head region, approximately $C_{0}=56 \mathrm{~kg} / \mathrm{m}^{3}$ for the baseline case, a dynamic balance is maintained with no net entrainment of the original soil matrix. In this case, the cohesion of the original soil matrix will have no bearing on the entrainment dynamics within the head region. Once the flow enters the channel, as the depositional layer is assumed to be permanent, the soil cohesion has minimal impact on the flow concentration as it only affects entrainment from the walls, $\eta_{e w}$. For the shallow flow case, the ratio of the contributing area of the gully walls to that from the floor is low 
(17\% versus $83 \%)$. If the inflow concentration exceeds the transport capacity of the flow, all deposited material will not be able to be immediately re-entrained. Mathematically a 'negative entrainment' will arise, which is equivalent to deposition not being actively re-entrained. This leads to the non-physical solution of higher flow concentrations arising for higher erosion resistances, which is an indicator the assumption of continuous re-entrainment has broken down. As the concentration decreases to below the transport capacity, this anomaly is corrected. Such a scenario would be rare, as it can reasonably be assumed that the transport capacity in the head region is greater than that in the gully drainage area. However, care must be taken to ensure that the model is not used in this case, as the underlying assumptions are invalid.

If the inflowing runoff is at the carrying capacity $C^{*}$, there will be no entrainment within the head region, and due to the assumption of no depositional layer forming, the concentration will stay constant within this region. Within the channel the depositional layer will form, and the concentration of the water column will decline. The rate at which the concentration declines will depend on the parameters. For the baseline case the concentration rapidly declines to the equilibrium value, whereas with a higher flux or lower settling velocity this decline is more gradual.

In general, the concentration of the inflowing runoff has only a transitory effect on the sediment flux within the gully. For an infinitely long gully the steady state within the channel, $\left.C_{\mathrm{SS}_{\mathrm{r}}}\right|_{x \rightarrow \infty}$ is independent of the inflowing runoff concentration. Therefore, if the gully is sufficiently long, the sediment flux exiting the gully will be independent of the concentration of the runoff, however patterns of entrainment and deposition within the gully will depend on the inflowing concentration. Gullies are not however infinitely long; as evident from Fig. 10, a greater inflowing sediment concentration will result in higher exiting sediment fluxes where full equilibrium has yet to be achieved. For the $100 \mathrm{~m}$ gully considered in this analysis, although the baseline parameter values achieve equilibrium within the gully, both the greater flow depth, (c) and (d), and the lower settling velocity, (e) and (f), generate a higher exit sediment flux with the high concentration inflow versus clean water inflow. 
Soil erosion resistances affect the sediment flux exiting gullies where the gully is insufficiently long, given other parameters, to achieve equilibrium concentrations. In the case of clean inflowing water, higher soil erosion resistances (compare $J=50 \mathrm{Ws} / \mathrm{kg}$ with the $J=$ $0 \mathrm{Ws} / \mathrm{kg}$ case) lead to lower sediment fluxes throughout the gully, as shown in Fig. 11. The effect of other parameters of the gully and the flow on the sediment flux exiting the gully are explored in Fig. 11 using a vary one-at-a-time approach under the case where the depositional layer is permanent. These parameters have a predictable effect on the exit flux. With all other parameters held fixed, increasing the gully width or flow depth increases the runoff flux, and hence stream and waterfall power, and therefore generates a higher sediment flux. As the erosive power decreases substantially in the transition from the head region to the channel, net deposition will occur and a longer gully will therefore correspond to a lower sediment flux. Once the gully reaches a certain length, approximately $35 \mathrm{~m}$ in the example case, an equilibrium is achieved whereby the erodibility characteristics of the sediment have only a minimal effect on the sediment flux exiting the gully. This is because of the assumption of a permanent depositional layer. The additional sediment entrained in the gully head due to a more erodible soil will deposit out over time (and hence distance). With sufficient distance, excess sediment carried in the flow will be fully deposited, and cease to influence local dynamics. Within the channel, the ratio of entrainment to re-entrainment is $W: 2 d$, which is $5: 1$ for the example case. Conversely, in the case where the underlying soil matrix is actively entrained throughout the channel, a longer gully will result in a greater sediment flux. As the depositional layer cannot form, entrainment will exceed deposition, continuously adding sediment to the water column leading to an increasing concentration with distance. Increasing either the sediment density or settling velocity will increase deposition, and therefore decrease the exit flux. In all cases, higher erosion resistances correspond to lower exit fluxes as the gully is more resistant to erosion.

In the case of a permanent depositional layer the concentration within the gully will trend to the constant value $\left[C^{*}\left(\widehat{\zeta}_{\text {ew }}+\widehat{\zeta}_{\mathrm{r}}\right)\right] /\left(\widehat{\delta}^{*}+\widehat{\zeta}_{\text {ew }}+\widehat{\zeta}_{\mathrm{r}}\right)$, for a sufficiently long gully. The size of this term is dependent on the balance between the erosive power of the flow relative to the soil's resistance, $k \Omega / J$, and the sediment characteristics of density, $\sigma$, and settling velocity 
$w_{s}$. If $k \Omega / J \gg 1 / w_{s}$, then the erosive power of the flow will dominate and the concentration within the gully will have minimal variation with sediment characteristics for a sufficiently long gully, as is the case for the baseline parameters shown.

[Figure 11 about here.]

\subsection{Interventions}

The MERGE model is shown to be suitable to represent gully interventions. Figs. 12 and 13 show the effect of increased ground cover and the installation of porous check dams on the sediment flux. For the highly erodible gully and a constant flux, increasing the ground cover within the gully results in a lower exit flux as expected. Although this example shows that erosion can be completely prevented through ground cover, this is not the case for all flow events. Porous check dams are shown to locally decrease the sediment flux at the location of each dam, resulting in a localised build up of the depositional layer. This result is consistent with observed behaviour. Porous check dams are known to trap sediment, building up behind the dam. This model therefore reproduces the key behaviour due to porous check dams, however as this model does not consider the effect of the depositional layer on the flow dynamics, there is no feedback loop between the depositional layer and the flux parameters of slope. Moreover, the water height relative to the height of the check dams is not updated throughout a simulation. Thus, to model longer term effects, updates to the slope and dam heights would be required.

[Figure 12 about here.]

[Figure 13 about here.]

\section{Concluding remarks}

This paper presents a new process-based model of gully erosion. MERGE will support the effective management of gullies to achieve improved environmental outcomes both locally and in connected ecosystems. MERGE incorporates the Hairsine and Rose concepts of ero- 
sion resistance and the depositional layer within a conservation of mass framework. The model takes as inputs physical characteristics of the gully and runoff event and outputs the concentration of sediment exiting the gully without any a priori knowledge of the history of erosion events at the site of interest. The sediment flux delivered to the riverine system is trivially calculated by multiplying the concentration with the known runoff flux to obtain the sediment flux.

The MERGE ideal gully model presents a significant improvement over existing models to capture the effect of rehabilitation interventions on the delivery of sediment from gully systems. While further work is required to parameterise the model, in particular relating the erosion resistance $J$ to common soil characteristics such as the R1 and R2 soil dispersion tests, and to validate against observations, MERGE exhibits many of the qualitative features of gully erosion. Features of erosion evident through the MERGE model include rapidly achieving a steady sediment concentration at the gully exit, evidence of hysteresis effects, the growth of a depositional layer, and first flush dynamics. Consideration of common interventions also demonstrated expected outcomes, including increased sediment deposition at the porous check dams, and the reduction (or prevention) of erosion with higher rates of ground cover. Future work will focus on validating the model against field observations, and improving the representation of sediment through consideration of a distribution of sediment sizes (and hence settling velocities). Incorporation of gravity-collapse process will present a significant advancement on the current model.

MERGE represents a significant advancement in gully erosion modelling. The model fills a gap in the availability of models to inform interventions. The simple analytical expressions obtained provide an opportunity to operatlionalise the MERGE model within decision support systems. 


\section{A Parameters}

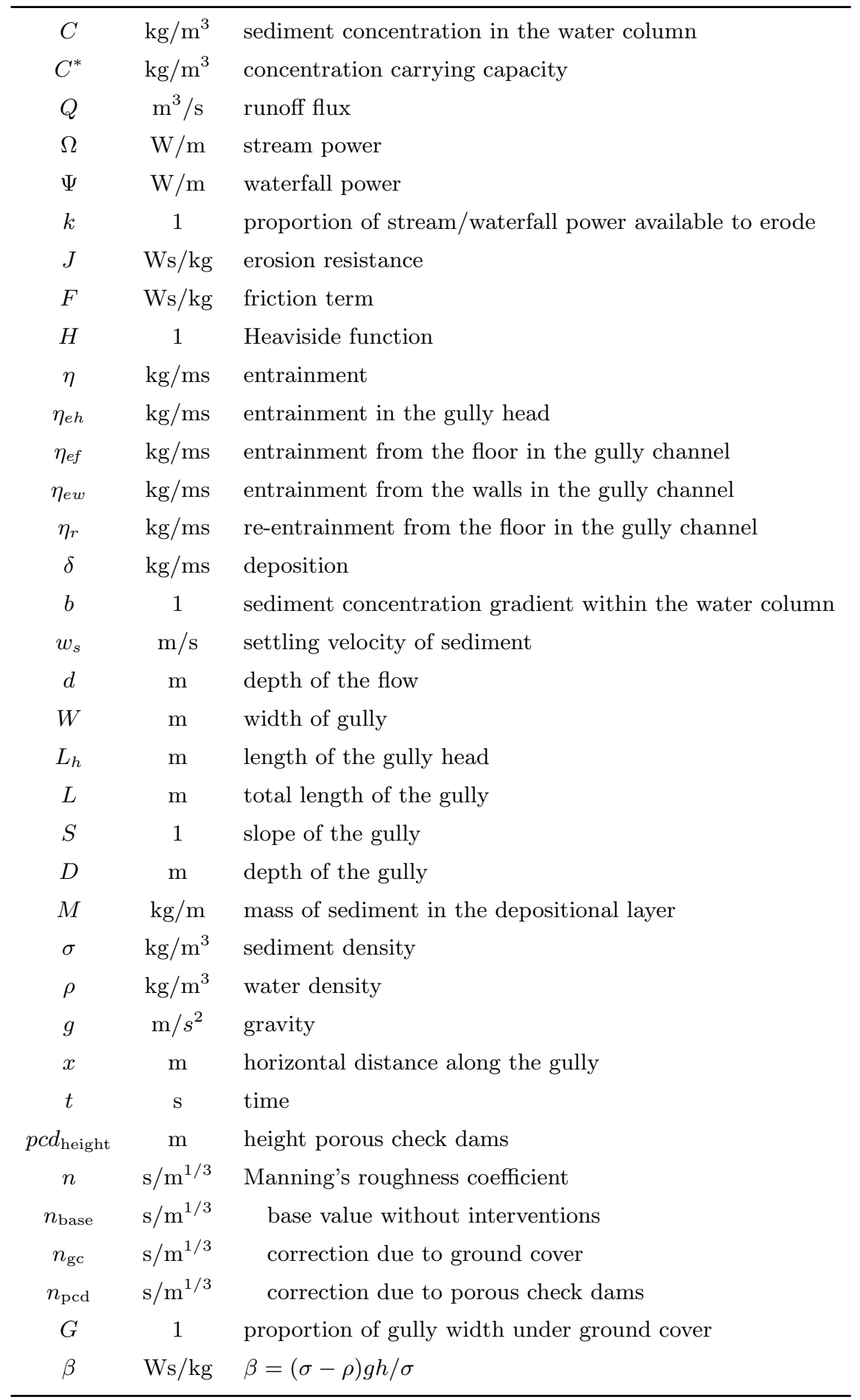




\section{Acknowledgments}

I would like to thank Evan Thomas (Department of Environment and Science), and David Hamilton and Bofu Yu (Griffith University), for useful discussions on the model; and Evan Thomas and Calvin Rose (Griffith University) for feedback on this manuscript. I thank the Queensland Water Modelling Network for facilitating discussions to understand the end-user requirements of the model, and to receive feedback on the model. This feedback lead to more realistic assumptions being used by the author. The author had final responsibility for the model design and all analysis.

This project has received funding support from the Queensland Government through the Queensland Water Modelling Network. The author's salary and travel is funded by the Queensland Water Modelling Network Research Fellowship.

The funder identified process-based models of gully erosion as a focus for the Fellowship, but had no further role in the study design, analysis or writing of this report. The author had final responsibility for the decision to submit for publication.

Conflict of Interest The author declares no conflicts of interest

\section{References}

Arcement Jr GJ, Schneider VR (1989) Guide for Selecting Manning's Roughness Coefficients for Natural Channels and Flood Plains. U.S. Geological Survey Water-Supply Paper 2339. Prepared in cooperation with U.S. Department of Transport, Federal Highway Administration.

Brooks AP, Spencer J, Doriean N, Pietsch TJ, Hacker J (2018) A comparison of methods for measuring water quality improvements from gully rehabilitation in great barrier reef catchments. In Proceedings of the 9th Australian Stream Management Conference (Hobart, Australia), 1-8.

Fukuoka S, Tabata K (2019) Derivation of the index governing the seepage flow and dynamic similarity condition of levee failures due to seepage flow. In River Basin Management X, volume 234 (Eds. Mambretti S, Melgarejo J) (WIT Press, Southampton). $63-70$. 
Garzon-Garcia A, Burton J, Franklin HM, Moody PW, De Hayr RW, Burford MA (2018) Indicators of phytoplankton response to particulate nutrient bioavailability in fresh and marine waters of the Great Barrier Reef. Science of the Total Environment 636, 1-12. 10.1016/j.scitotenv.2018.04.334.

Great Barrier Reef Marine Park Authority (2019) Great Barrier Reef Outlook Report 2019. URL http://hdl.handle.net/11017/3474.

Hairsine PB (1988) A physically based model of the erosion of cohesive soils. Phd thesis, Griffith University.

Hairsine PB, Moran CJ, Rose CW (1992) Recent developments regarding the influence of soil surface characteristics on overland flow and erosion. Australian Journal of Soil Research 30 (3), 249-264.

Hairsine PB, Rose CW (1992a) Modeling water erosion due to overland flow using physical principles: 1. Sheet flow.

Water Resources Research 28, 237-243. 10.1029/91WR02380.

Hairsine PB, Rose CW (1992b) Modeling water erosion due to overland flow using physical principles: 2. Rill flow. $\quad$ Water Resources Research 28(1), 245-250. 10.1029/91WR02381.

Prosser IP (2018) Improving how gully erosion and river sediment transport processes are represented in Queensland catchment models. https://www.des.qld.gov.au/ science/documents/qwmn-gully-erosion-processes-report.pdf.

Roberts ME (2019) The erosion of an ideal gully under steady state conditions. In 23rd International Conference on Modelling and Simulation (Canberra, Australia). 10.36334/modsim.2019.G1.roberts.

Rose CW, Shellberg JG, Brooks AP (2015) Modelling suspended sediment concentration and load in a transport-limited alluvial gully in northern Queensland, Australia. Earth surface processes and landforms 40(10), 1291-1303. 10.1002/esp.3720.

Rose CW, Yu B, Ward DP, Saxton NE, Olley JM, Tews EK (2014) The erosive growth of hillside gullies. Earth Surface Processes and Landforms 39(15), 1989-2001. 10.1002/esp.3593. 
Schiesser WE (1991) The numerical method of lines: integration of partial differential equations (Academic Press).

Waterhouse J, Schaffelke B, Bartley R, Eberhard R, Brodie J, Star M, Thorburn P, Rolfe J, Ronan M, Taylor B, Kroon F (2017) 2017 Scientific Consensus Statement. URL https://www.reefplan.qld.gov.au/about/assets/2017-scientific-consensus -statement-summary.pdf.

Wilkinson S, Hairsine P, Brooks A, Bartley R, Hawdon A, Pietsch T, Shepherd B, Austin J (2019) Gully and Stream Bank Toolbox. A technical guide for the Reef Trust Gully and Stream Bank Erosion Control Program (Commonwealth of Australia), 2nd edition.

Wilkinson S, Henderson A, Chen Y (2008) SedNet User Guide, 2.0 edition.

URL https://toolkit.ewater.org.au/Tools/SedNet/documentation.

Wooldridge SA (2017) Preventable fine sediment export from the Burdekin River catchment reduces coastal seagrass abundance and increases dugong mortality within the Townsville region of the Great Barrier Reef, Australia. Marine Pollution Bulletin 114(2), 671-678. 10.1016/j.marpolbul.2016.10.053. 


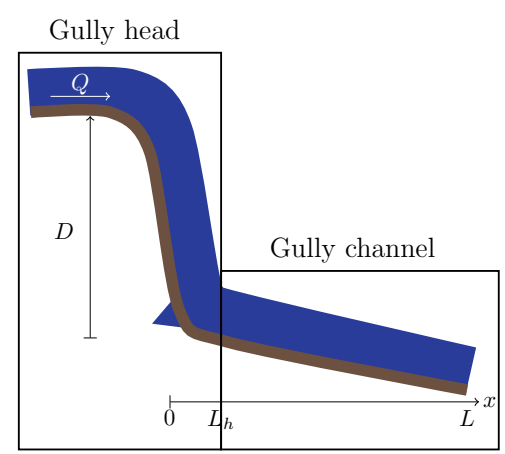

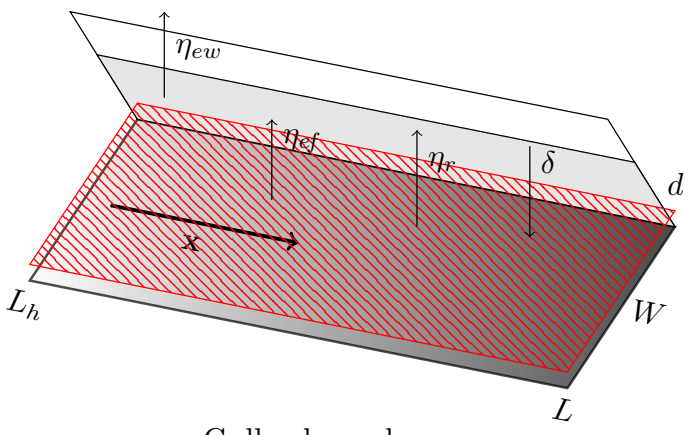

Gully channel

Figure 1: Geometry of the ideal gully. The sediment concentration $C(x, t)\left[\mathrm{kg} / \mathrm{m}^{3}\right]$ satisfies the conservation of mass equation, which is to be solved within the bounded domain $x \in[0, L]$, for time $t \geq 0$. The gully is split into two regions for convenience, the gully head $x \in\left[0, L_{h}\right]$, and the channel $x \in\left(L_{h}, L\right]$, for time $t \geq 0$. The gully is of constant slope. The flow within the gully is of constant flux $Q\left[\mathrm{~m}^{3} / \mathrm{s}\right]$ with depth $d[\mathrm{~m}]$, and width $W[\mathrm{~m}]$. Sediment is entrained from the walls and floor at rate $\eta_{e w}[\mathrm{~kg} / \mathrm{ms}]$ and $\eta_{e f}[\mathrm{~kg} / \mathrm{ms}]$ respectfully, and re-entrained at the rate $\eta_{r}[\mathrm{~kg} / \mathrm{ms}]$. Sediment is deposited out at the rate $\delta[\mathrm{kg} / \mathrm{ms}]$ forming the depositional layer (shown in red). Within the gully head a depositional layer is not formed, as deposited sediment is immediately re-entrained. Net entrainment in the gully head is at the rate $\eta_{e h}[\mathrm{~kg} / \mathrm{ms}]$. 

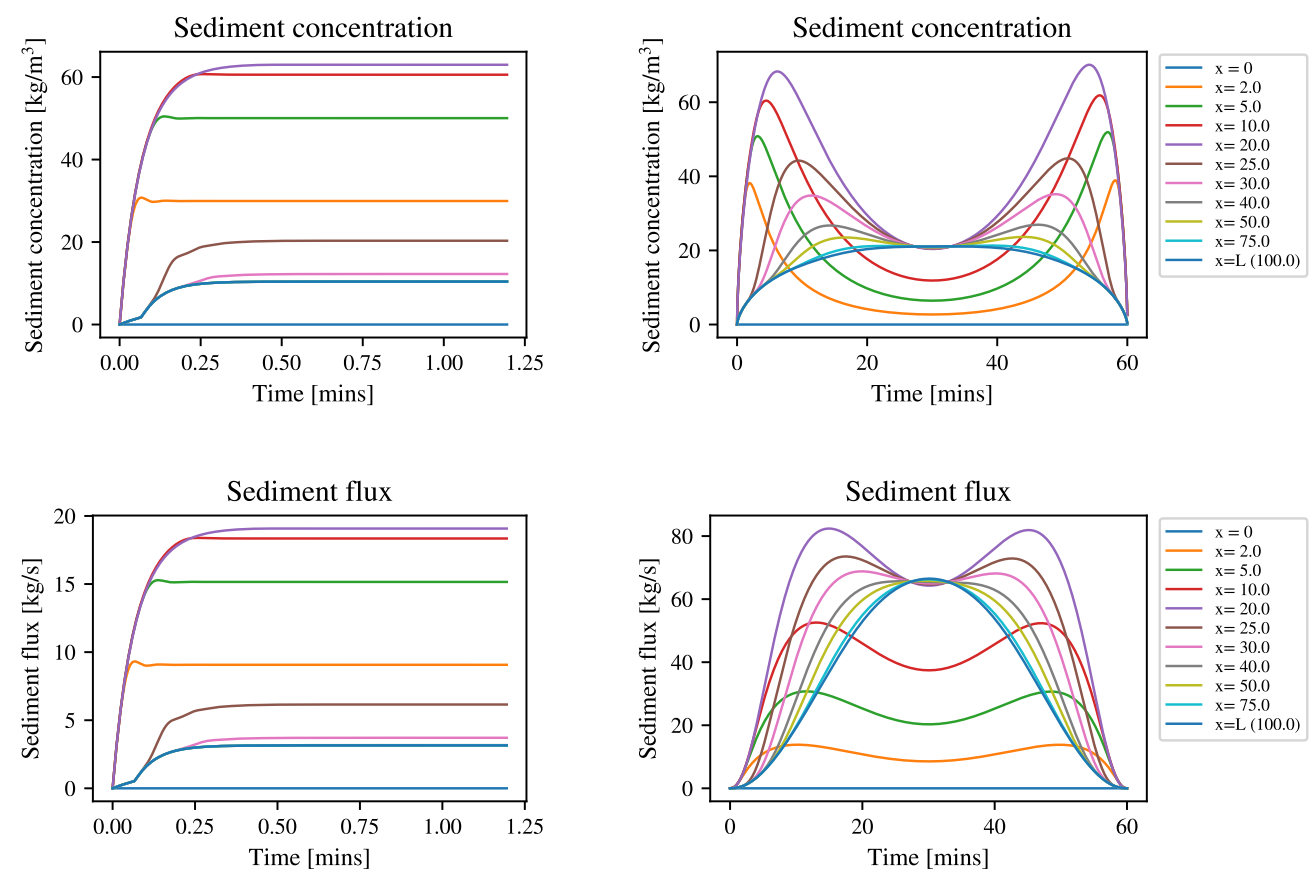

(a) $d(t)=0.2 \mathrm{~m}$

(b) $d(t)=\sin (\pi t / 3600)+0.001 \mathrm{~m}$

Figure 2: Concentration and sediment flux dynamics for a constant (a) and dynamic (b) runoff flux for a highly erodible gully at specific locations within the gully. 

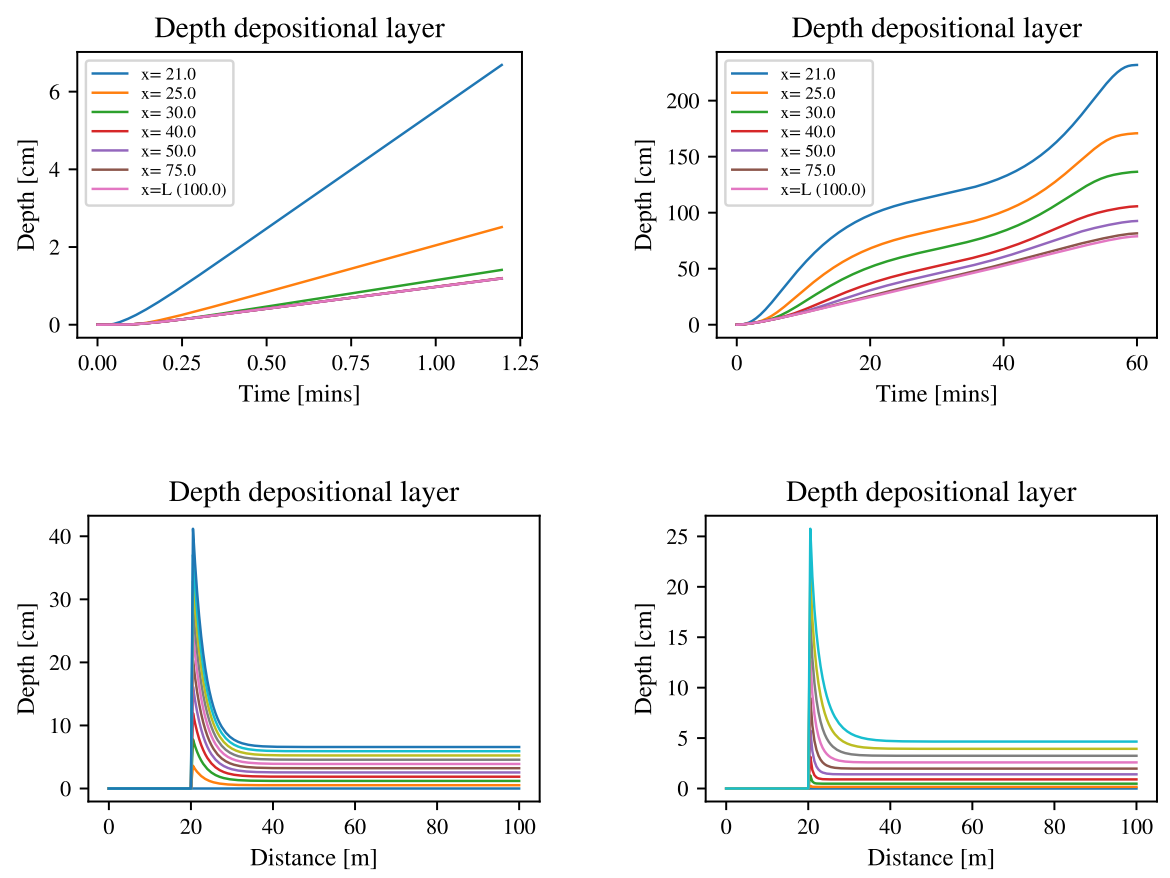
(a) $d(t)=0.2 \mathrm{~m}$
(b) $d(t)=\sin (\pi t / 3600)+0.001 \mathrm{~m}$

Figure 3: Dynamics of the depositional layer under constant (a) and dynamic (b) runoff flux conditions in a highly erodible gully. The growth of the depositional layer is shown at a selection of locations within the gully channel. The growth of the depositional layer within the gully is shown for times up to 6 min for the constant case (a), and over the full hour for the dynamic case (b). All other parameter values are as per Table 1. 

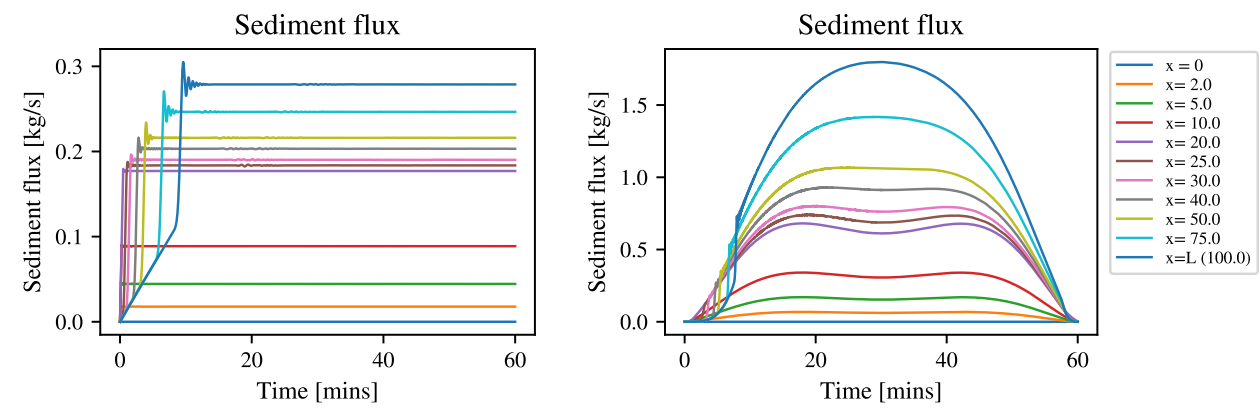

Figure 4: Concentration and sediment flux dynamics for a constant (a) and dynamic (b) runoff flux for a gully that is resistant to erosion (high erosion resistance) at specific locations within the gully. 

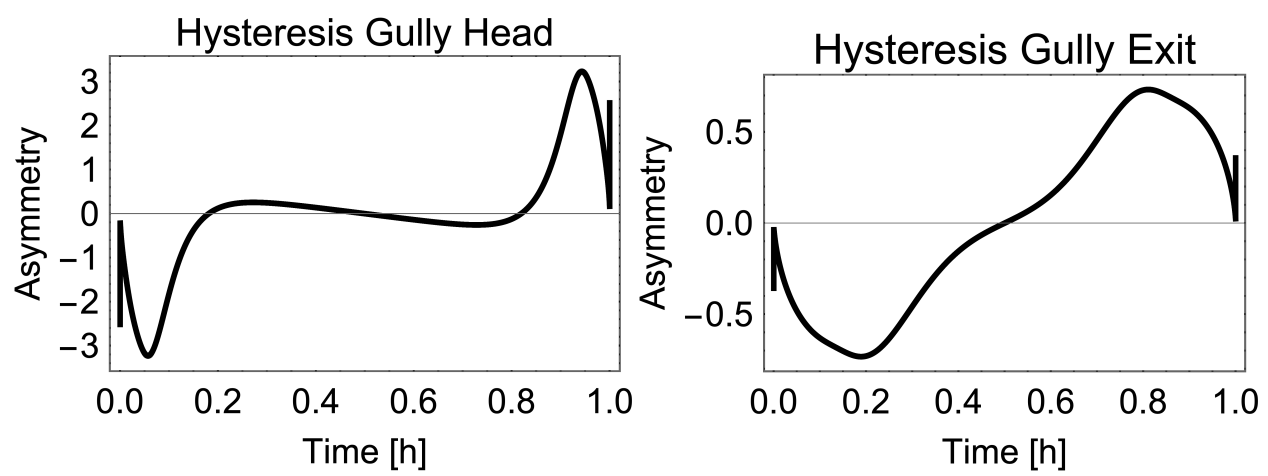

Figure 5: Hysteresis effects for the sinusoidal flow depth in a highly erodible gully. Hysteresis is indicated by the asymmetry in the sediment concentration $\left[\mathrm{kg} / \mathrm{m}^{3}\right]$ between the rising and falling hydrographs. 


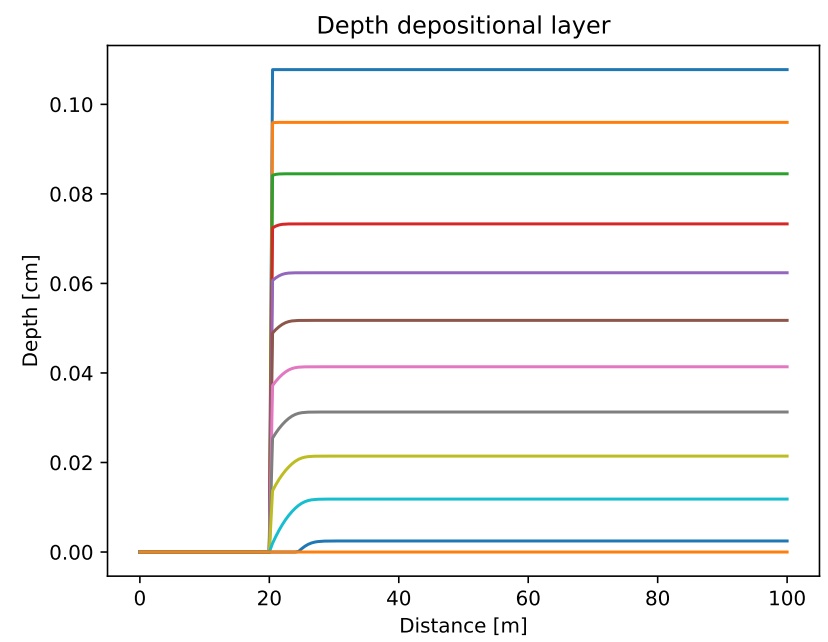

Figure 6: First flush effects due to an initial depositional layer of $M_{0}=5 \mathrm{~kg} / \mathrm{m}$, approximately $0.1 \mathrm{~cm}$ deep, in a gully that is highly resistant to erosion $J=400 \mathrm{Ws} / \mathrm{kg}$, with a high runoff flux corresponding to $d=1 \mathrm{~m}$. Solutions are shown at equal time intervals, with the depositional layer decreasing over time. 


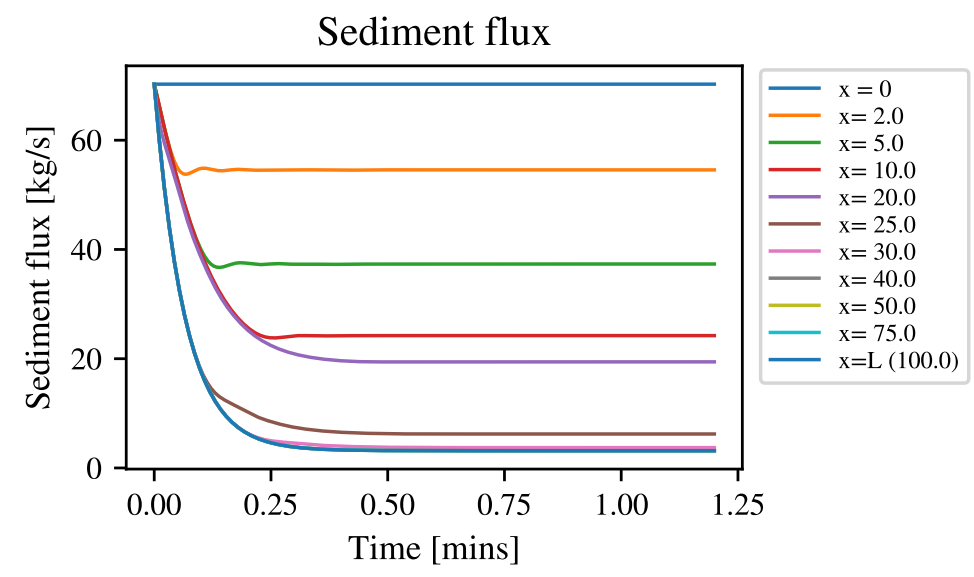

Figure 7: Sediment flux dynamics with a constant runoff flux and an incoming runoff concentration of $C_{0}=C^{*} / 2 \mathrm{~kg} / \mathrm{m}^{3}$ at different locations within a highly erodible gully. 


\section{Constant flux}

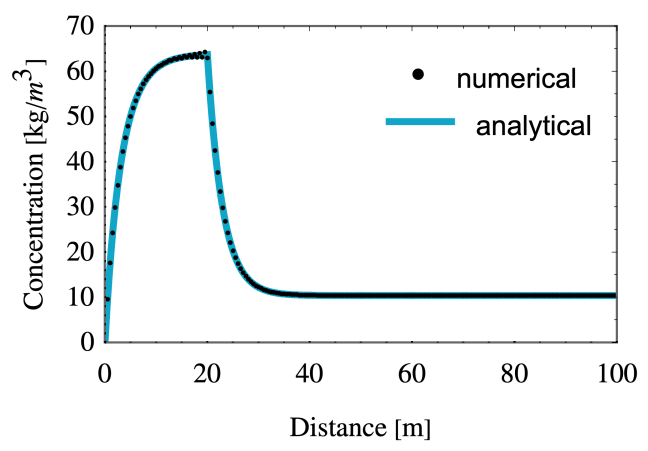

Figure 8: Comparison of the analytical steady state concentration with the long time $(t=6 \mathrm{~min})$ numerical solution for a highly erodible gully with a runoff depth of $d=0.2 \mathrm{~m}$. 


\section{Dynamic flux}

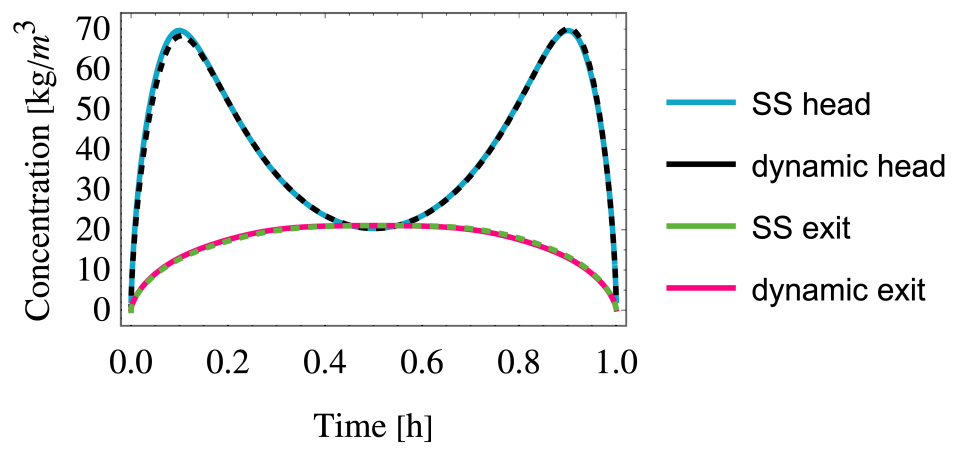

Figure 9: Comparison of the numerical (dynamic) and the analytical steady state (SS) solutions for a dynamic runoff flux, $d=\sin (\pi t / 3600)+0.001 \mathrm{~m}$, in a highly erodible gully. Sediment concentrations are shown at the end of the gully head $\left(x=L_{\mathrm{h}}\right)$ and at the gully exit $x=L$. 


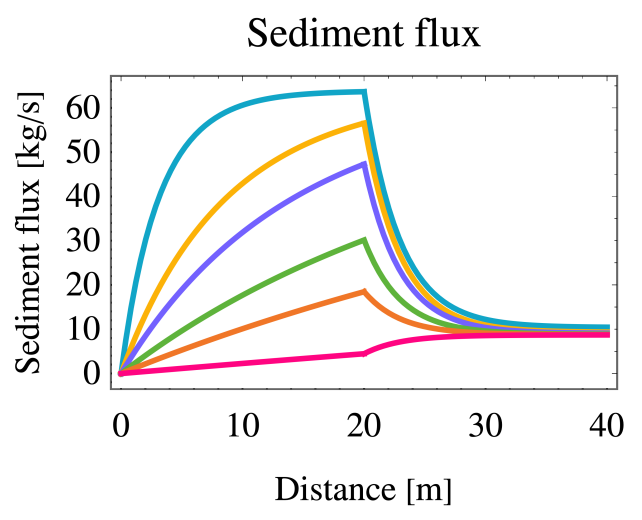

(a) $d=0.2, w_{s}=0.05, C_{0}=0$

\section{Sediment flux}

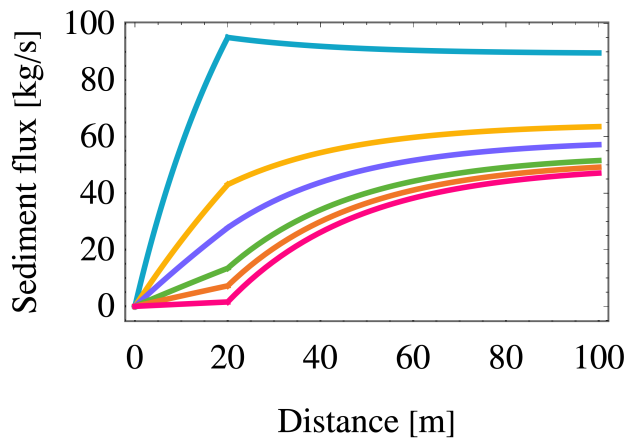

(c) $d=1, w_{s}=0.05, C_{0}=0$

Sediment flux

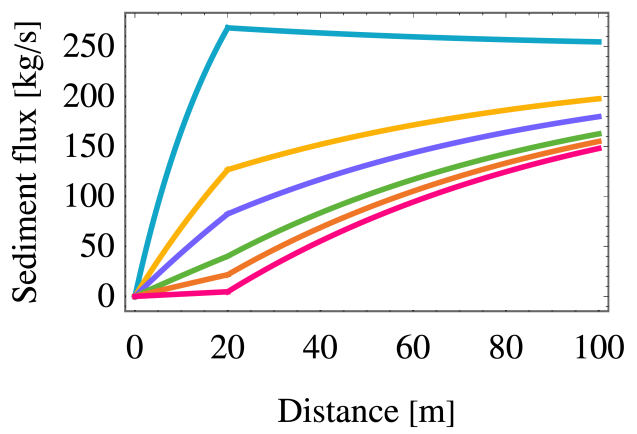

(e) $d=0.2, w_{s}=0.001, C_{0}=0$
Sediment flux

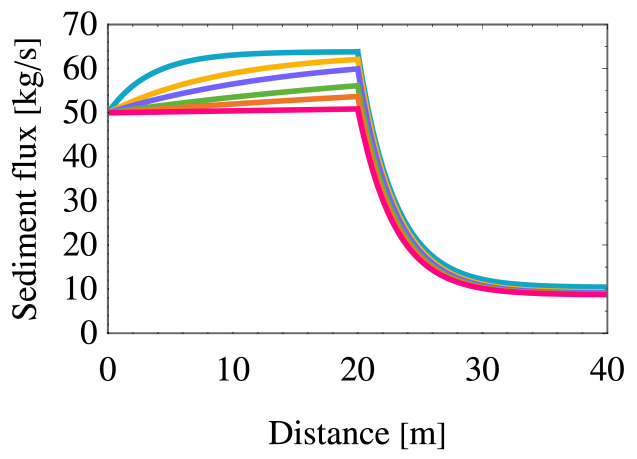

(b) $d=0.2, w_{s}=0.05, C_{0}=50$

Sediment flux

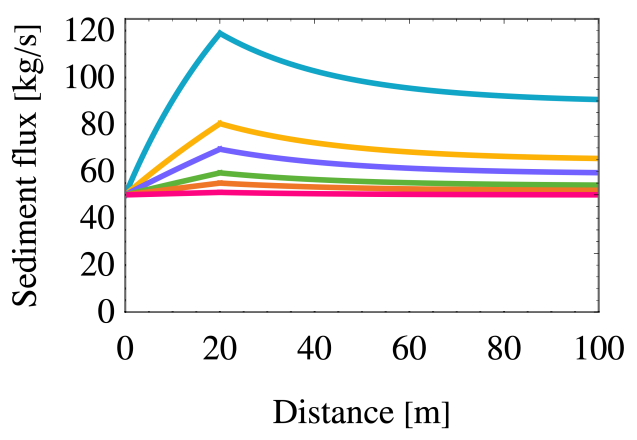

(d) $d=1, w_{s}=0.05, C_{0}=50$

\section{Sediment flux}

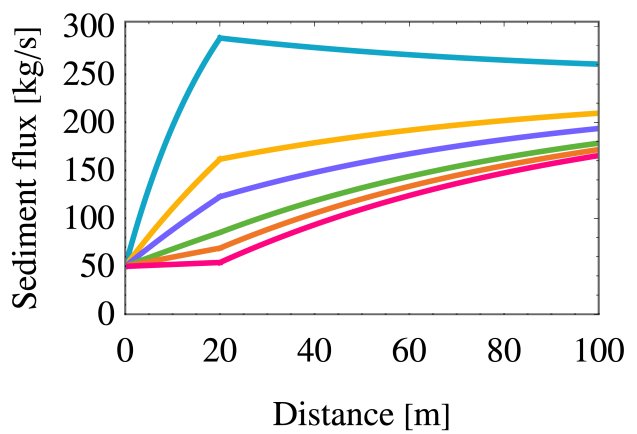

(f) $d=0.2, w_{s}=0.001, C_{0}=50$

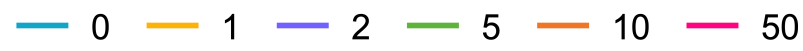

Figure 10: Sediment flux within the gully for a selection of erosion resistances between $J=0 \mathrm{Ws} / \mathrm{kg}$ and $J=50 \mathrm{Ws} / \mathrm{kg}$. Solutions are obtained using the analytical steady state results. Parameter values are as per Table 1 unless otherwise indicated. The units for the flow depths $d$, settling velocities, $w_{s}$ and initial concentration, $C_{0}$ are $\mathrm{m}, \mathrm{m} / \mathrm{s}$, and $\mathrm{kg} / \mathrm{m}^{3}$ respectively. 


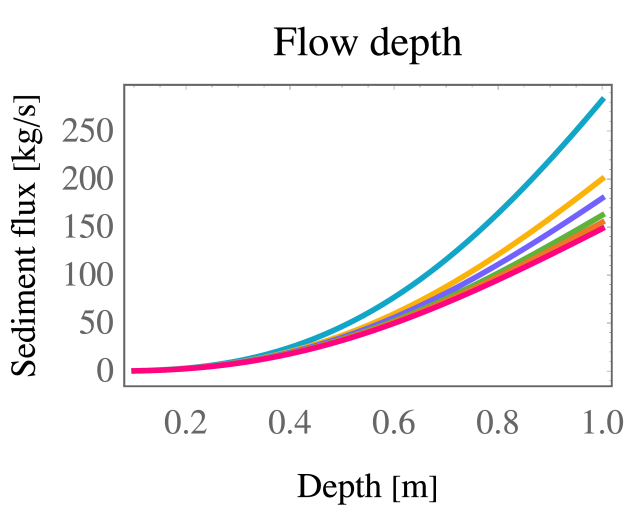

Gully width

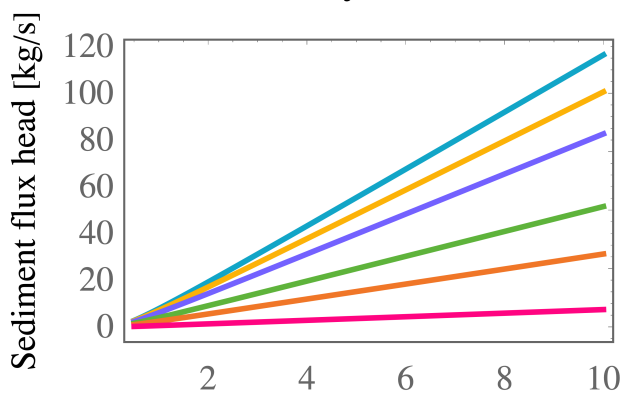

Gully width [m]

Settling velocity

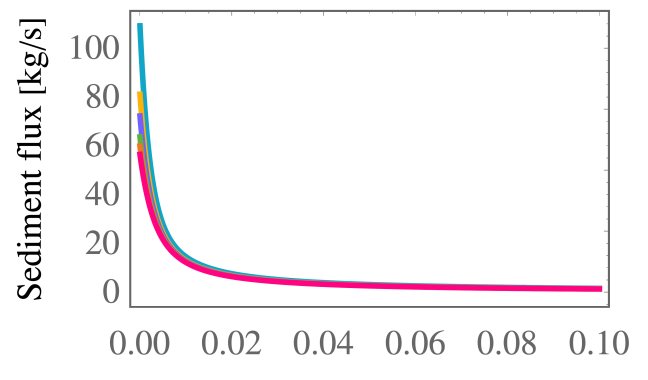

Settling velocity $[\mathrm{m} / \mathrm{s}]$

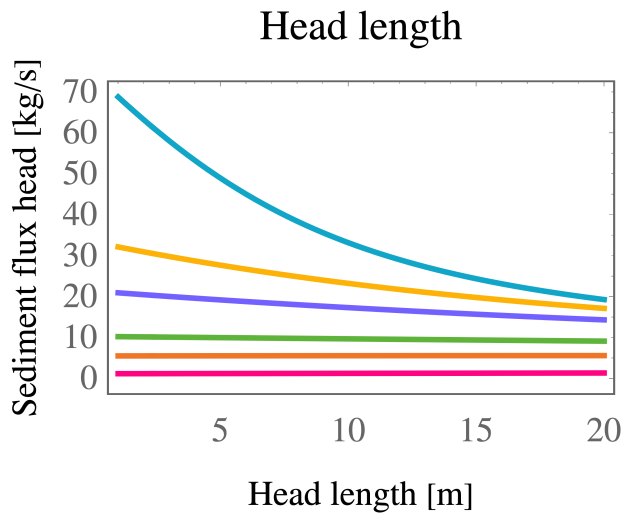

Gully length

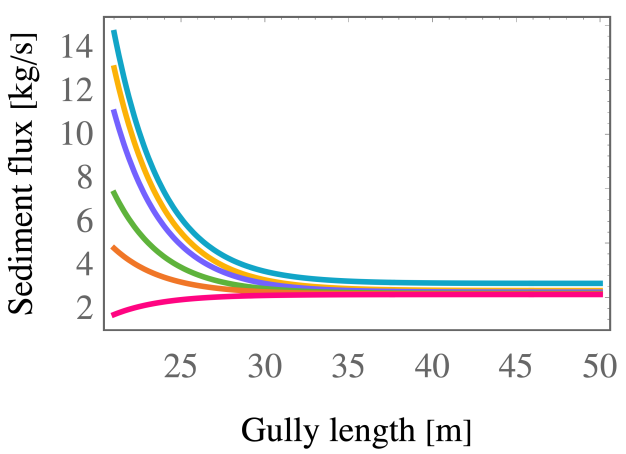

Sediment density

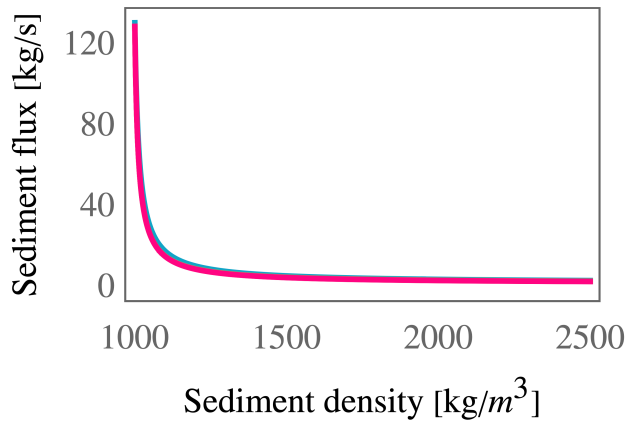

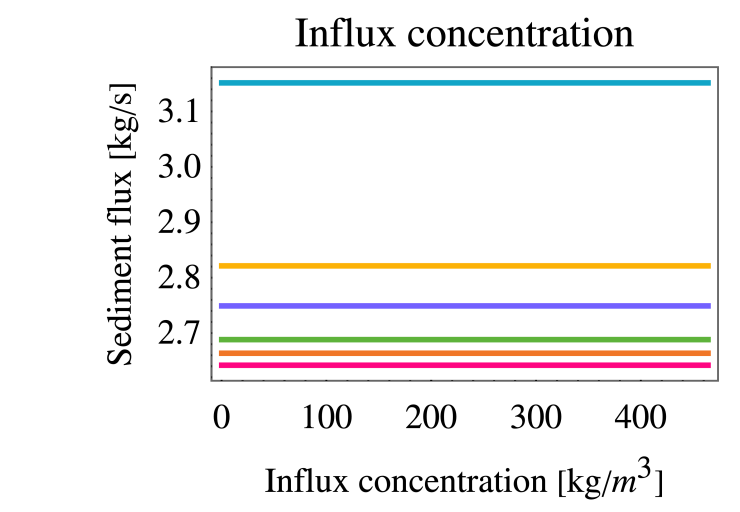

$-0-1-2-5-10-50$

Figure 11: Sediment flux at the gully exit as a function of the gully parameters for a range of erosion resistance values between $J=0 \mathrm{Ws} / \mathrm{kg}$ and $J=50 \mathrm{Ws} / \mathrm{kg}$ from the analytical steady state solutions and assuming a permanent deposition layer, (12), and a constant flux depth $d=0.2 \mathrm{~m}$. The effect of head length and gully width are shown at the start of the channel (indicated by 'Sediment flux head' on the y-axis), as it was not found to be significant by the end of the gully. 


\section{Sediment flux}

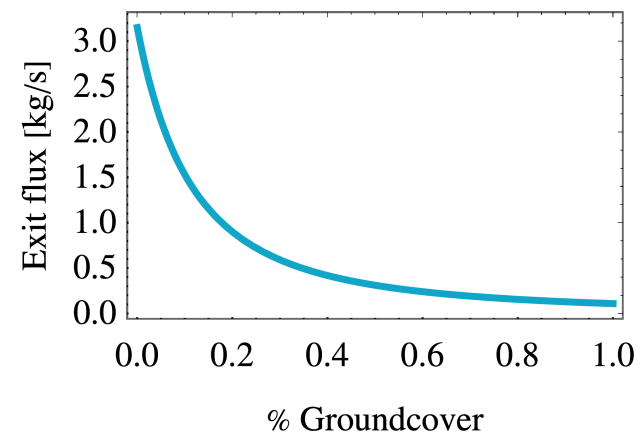

Figure 12: Exiting sediment flux as a function of the proportion of ground cover within the gully for Run A obtained from the analytical steady state solutions. 
Sediment Flux

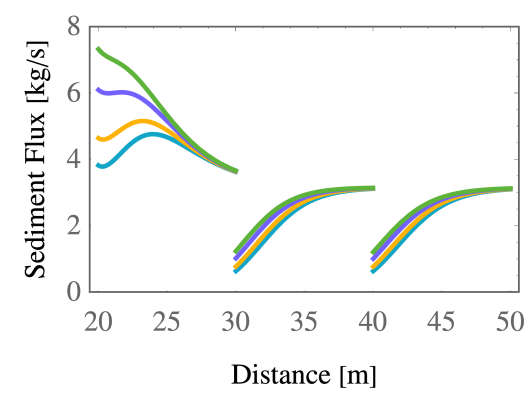

(a) $d=0.4,0.6,0.8$ and $1 \mathrm{~m}$

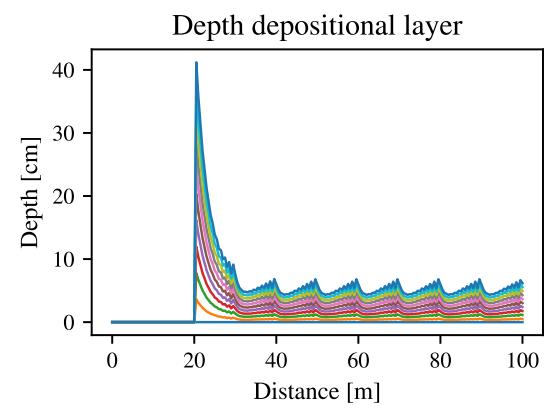

(b) $d=0.2 \mathrm{~m}$

Figure 13: Effect of porous check dams on the sediment flux (a) and depositional layer (b). The sediment flux results were obtained from the analytical steady state results, and the depositional layer using the numerical solution. $50 \mathrm{~cm}$ high porous check dams are installed every $10 \mathrm{~m}$, commencing at $L_{h}+10$ for a highly erodible gully. (a) Sediment flux exiting the gully given by the steady state solutions (15) and (15), with higher flow depths corresponding to higher fluxes. (b) Depth of the depositional layer throughout the gully for increasing time up to $t=6 \mathrm{~min}$, with the solution obtained using the fully dynamic model. 


\begin{tabular}{lcrlcr}
\hline Sediment density & $\sigma$ & $2320 \mathrm{~kg} / \mathrm{m}^{3}$ & Settling velocity & $w_{s}$ & $0.05 \mathrm{~m} / \mathrm{s}$ \\
Slope & $S$ & 0.01 & Gully depth & $D_{0}$ & $1.2 \mathrm{~m}$ \\
Head length & $L_{h}$ & $20 \mathrm{~m}$ & Gully length & $L$ & $100 \mathrm{~m}$ \\
Width & $W$ & $2 \mathrm{~m}$ & Fluid density & $\rho$ & $1000 \mathrm{~kg} / \mathrm{m}^{3}$ \\
Gravity & $g$ & $9.81 \mathrm{~m} / \mathrm{s}$ & Power proportion & $k$ & 0.02 \\
Friction term & $F$ & $0 \mathrm{Ws} / \mathrm{kg}$ & Concentration gradient & $b$ & 1 \\
Initial concentration & $C_{0}$ & $0 \mathrm{~kg} / \mathrm{m}^{3}$ & Initial layer mass & $M_{0}$ & $0 \mathrm{~kg}$ \\
Carrying capacity & $C^{*}$ & $0.2 \sigma \mathrm{kg} / \mathrm{m}^{3}$ & Manning's roughness* & $n$ & $0.04 \mathrm{~s} / \mathrm{m}^{1 / 3}$ \\
Erosion resistance (high) & $J$ & $400 \mathrm{Ws} / \mathrm{kg}$ & Erosion resistance $(l o w)$ & $J$ & $\frac{400}{3600^{2}} \mathrm{Ws} / \mathrm{kg}$ \\
Height check dam & \multicolumn{1}{c}{ pcd height } & $0.5 \mathrm{~m}$ & & & \\
\hline
\end{tabular}

Table 1: Fixed parameter values used for exploring steady state and dynamic solutions. *Manning's roughness is modified to represent interventions, for simulations with interventions, this is the base Manning's roughness number $n_{\text {base }}$. 